\title{
Complete Esophageal Clearance Following Swallowing
}

National Cancer Institute

\section{Source}

National Cancer Institute. Complete Esophageal Clearance Following Swallowing. NCI

Thesaurus. Code C127344.

A finding of complete esophageal clearance following swallowing. 